\title{
The effect of dietetic management on weight in children with Bardet-Biedl Syndrome
}

Dr Muzzammil Ali, Dr Suma Uday, Waseema Azam, Prof Barrett

Birmingham Children's Hospital, Birmingham, UK

\section{INTRODUCTION}

Bardet-Biedl syndrome (BBS) is a monogenic disease characterized by retinitis pigmentosa( $>90 \%)$, obesity $(72-86 \%)$, insulin resistant diabetes, and hypogonadism 1 . Mutations in at least 15 genes have been described in patients with this syndrome ${ }^{2}$. Disordered function of the primary cilia may also be a fundamental defect ${ }^{3}$. Weight management is challenging in this group of patients due to the frequent association with intellectual disabilities and visual impairment.

At our BBS MDT clinic, dietetic review is provided at each visit. Dietetic input focuses primarily on reduced fat and sugar content in diet, and regular exercise is encouraged. Individualised tailored dietary plans are provided for each patient.

\section{AIMS AND OBJECTIVES}

To assess the effect of dietetic input on BMI-SDS in BBS children

\section{METHODS}

All children attending our MDT BBS clinic between January 2007-December 2014 with at least 3 years follow-up data were included. Paired t-test using SPSS was performed to compare the mean difference in BMI-SDS at baseline and follow-up.

Paired t-test using SPSS was performed to compare the mean difference in BMI-SDS at baseline and at follow-up.

\section{RESULTS}

\begin{tabular}{|c|c|c|c|}
\hline & All & $\begin{array}{c}\text { GROUP A } \\
<5 \text { YEARS AT } \\
\text { BASELINE }\end{array}$ & $\begin{array}{c}\text { GROUP B } \\
>5 \text { YEARS AT } \\
\text { BASELINE }\end{array}$ \\
\hline NUMBER OF PATIENTS & 48 & 10 & 38 \\
\hline $\begin{array}{l}\text { MEDIAN (RANGE) AGE AT } \\
\text { BASELINE }\end{array}$ & $\begin{array}{c}8.1 \\
(0.9-15.1)\end{array}$ & $\begin{array}{c}2.4 \\
(1-4.4)\end{array}$ & $\begin{array}{c}9.7 \\
(5.01-15.1)\end{array}$ \\
\hline BMI-SDS BASELINE & $3.14( \pm 1.1)$ & $3.8( \pm 1.7)$ & $2.8( \pm 0.68)^{*}$ \\
\hline $\begin{array}{l}\text { BMI-SDS } 2 \text { YEARS } \\
\text { FOLLOW UP }\end{array}$ & $3.16( \pm 1)$ & $4.4( \pm 1.2)$ & $2.7( \pm 0.7)$ \\
\hline $\begin{array}{l}\text { BMI-SDS } 3 \text { YEARS } \\
\text { FOLLOW UP }\end{array}$ & $3.18( \pm 0.9)$ & $4.5( \pm 0.88)$ & $2.6( \pm 0.6)^{*}$ \\
\hline
\end{tabular}

Table 1: BMI-SDS at baseline and follow up in all patients and in Group A $(<5$ years at baseline) and Group $B\left(>5\right.$ years at baseline). ${ }^{*}$ The reduction in BMI-SDS at baseline and 3 years in Group B was not statistically significant $(p=0.19)$.

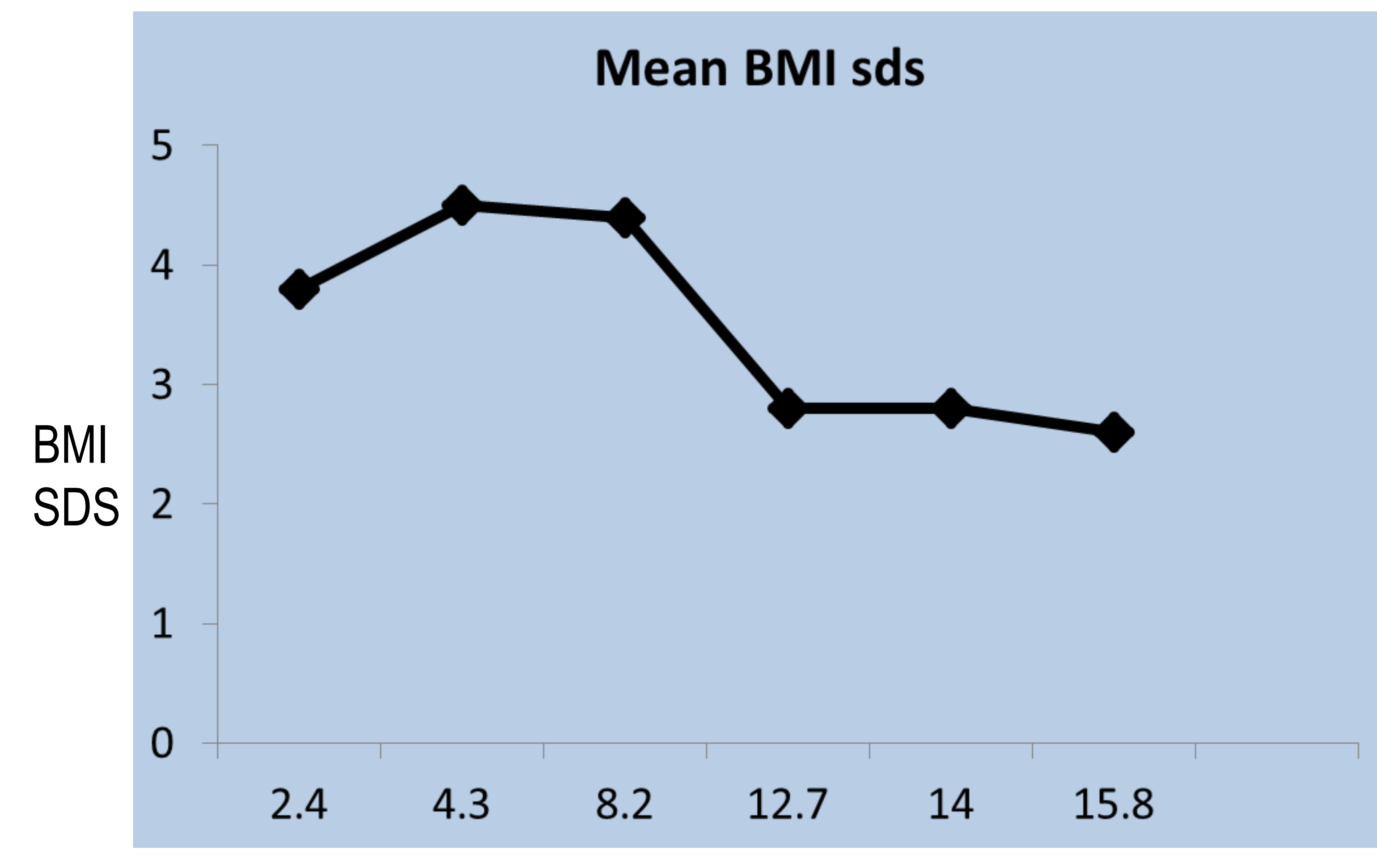

Age in years

Figure 1. BMI SDS at baseline and follow up for all age groups showing highest BMI SDS in the younger age groups
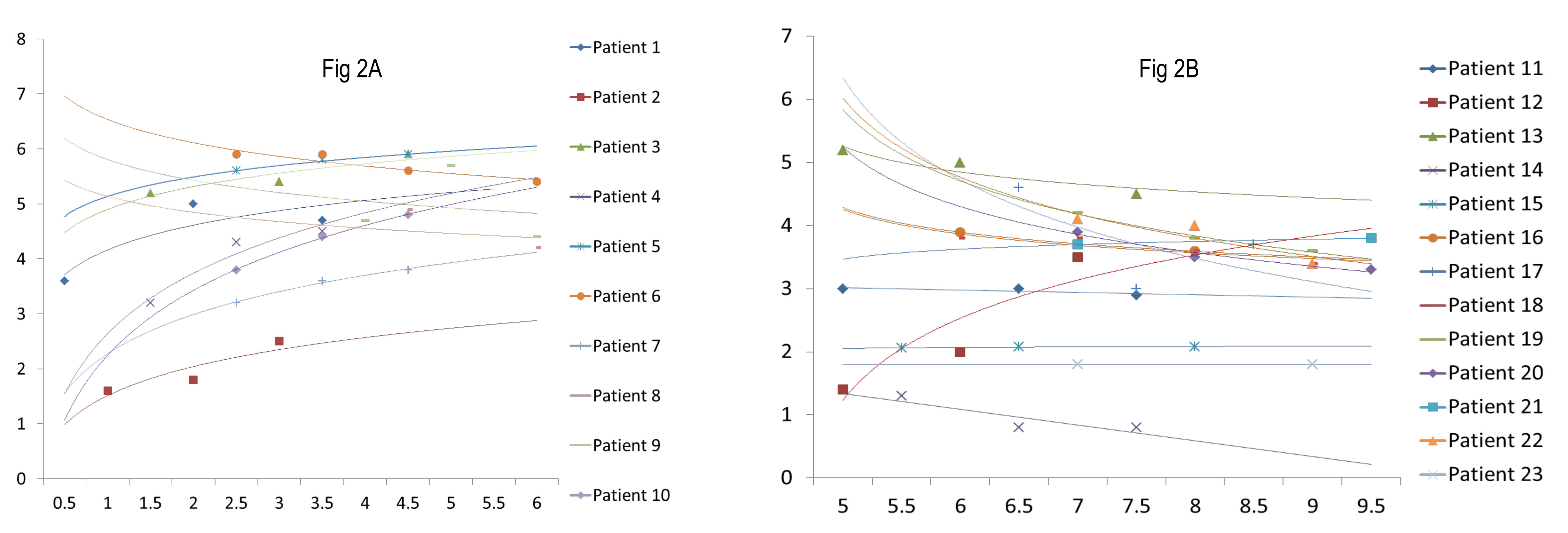

Figure 2 shows individual patient trajectories for BMI SDS from baseline to 3 years follow up with age in years on $x$-axis and BMI-SDS on y-axis.

Fig $2 A$ ( $<5$ years at baseline) demonstrates rising BMI SDS in majority of the patients Fig 2B (5-8 years at baseline) shows a plateau or reduction in BMI SDS in majority of the patients

Fig 2C (8-13 years at baseline) shows a reduction in BMI SDS in majority of the patients Fig 2D (13- 14 years at baseline) shows a plateauing of BMI SDS in most patients

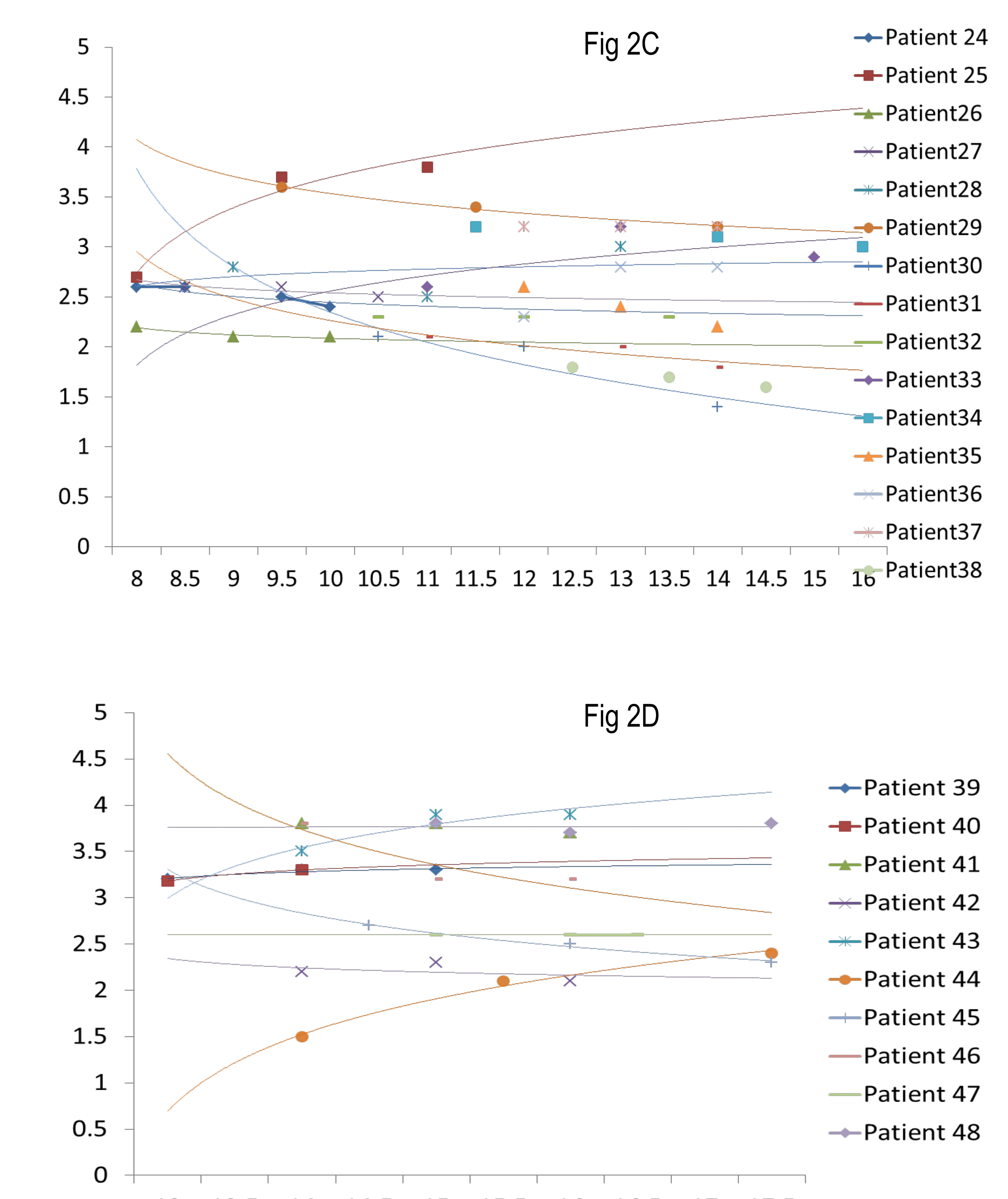

\section{CONCLUSION}

We hypothesise that the excess weight gain in early life may be attributed to delayed walking and difficulties in dietary restriction. Despite the increased risk of weight gain in later childhood associated with visual impairment, provision of individualised dietary plans are associated with a non-significant trend towards BMI-SDS reduction.

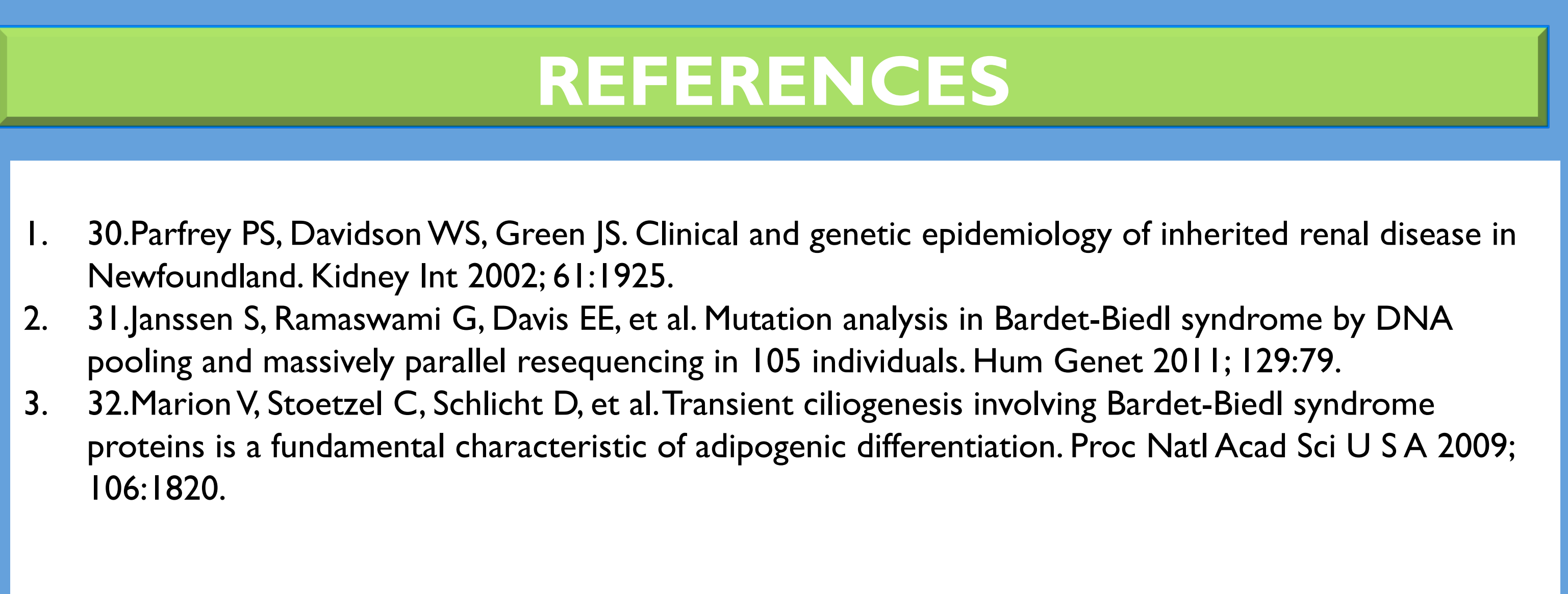

